\author{
Military Technical College \\ Kobry El-Kobbah, \\ Cairo, Egypt
}

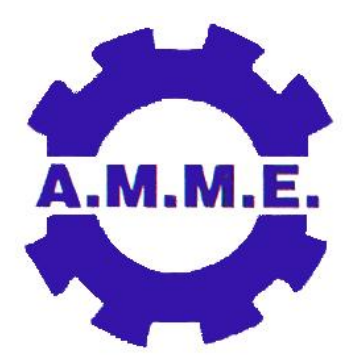

$14^{\text {th }}$ International Conference on Applied Mechanics and Mechanical Engineering.

\title{
Computational Techniques for Calculation of Missile Aerodynamic Coefficients
}

\author{
By \\ Mandour, M.F.* Mahmoud, O.K* Abdalla, H.M **
}

\begin{abstract}
:
Studying the flow over bodies of revolution is crucial to the design of missiles and obtaining the correct shape which has a large impact on the performance of the missile. Threedimensional flow simulation over a body of revolution were carried out in order to obtain flow field parameters for different angles of attack namely $-4.09,-2.04,2.06,4.11,6.17$ and $12.41^{\circ}$ at Mach number of 0.5 (subsonic) and of $-4.34,-2.15,2.17,4.37,8.87$, and $13.6^{\circ}$ at Mach number of 1.2 ( transonic flow conditions). The software FLUENT with its prepressor GAMBIT were used to model a missile of known geometry. The Computational Fluid dynamics results were validated with a pre-published experimental data measured by a wind tunnel [1]
\end{abstract}

The validated model was used to examine Magnus effect on the spinning missile which improves the effect of the high spinning rate on the side force affecting the missile body.

\section{Keywords:}

CFD, aerodynamic, Magnus effect. 
* Egyptian Armed Forces

** Military Technical Collage

\section{Introduction:}

Aerodynamic forces are divided into two main components: drag and lift. The drag, lift and moment coefficients are dimensionless quantities that describe the amount of aerodynamic drag, lift and moment caused by fluid flow. There are basically three approaches that can be used to obtain the flow properties around a flying body. These approaches are experimental, numerical and analytical methods.

Experimental studies are conducted mainly in wind tunnels. A model of the concerned configuration is to be designed and constructed. This model must have provisions for measuring the wall pressures, and it should be compatible with the existing wind tunnel facility. The wind tunnel facility must be capable of producing the required free stream conditions in the test section. The problem of matching flow conditions in a wind tunnel can often prove to be quit troublesome. Since high speed wind tunnels require large amounts of energy for their operation, the wind tunnels test time must be kept to a minimum. Experimental approach has the capability of producing the most realistic answers for many flow problems; however, the costs are becoming greater every day.

In the theoretical approach, simplifying assumptions are used in order to make the problem tractable. The big advantage of the theoretical approach is that, general information can be obtained in many cases from a simple formula. This approach is quite useful in the preliminary design work, since reasonable answer can be obtained in a minimum amount of time.

In the computational approach, a limited number of assumptions are made and a high-speed digital computer is used to solve the resulting governing fluid dynamic equations. Generally, computational approach is used to minimize the number of experiments. Computational work which is used in this study have attracted many researcher in field of aerodynamics. A summery of these work is presented in the following section.

Byung-Young, et al [2] investigated computationally the supersonic flow around the lateral jet controlled missile. A three-dimensional Navier-Stockes computer code (AADL 3D) has been developed and case studies have been performed by comparing the normal force and the moment coefficients of the missile body. To check whether the developed code correctly predict the supersonic flow field around the missile body, the calculated surface pressure distribution on an ogive-cylinder body are compared with the experimental measurement results from wind tunnel at angles of attack of $0^{\circ}, 5^{\circ}, 10^{\circ}$. The free stream Mach number was 1.98. The computational grid was $70 \times 40 \times 40$ for a half body (112000 cells).

Parise [3] investigated computationally the choked flow. The projectile of interest was based on the air force finer body, with four grids. All CFD simulations presented were made with ANSYS CFX 5.7 which is a commercial CFD code. In the supersonic regime, comparison between experimental and numerical results is very good. The numerical results followed the 
trends illustrated by the wind tunnel results. As for normal force coefficient results, comparison between CFD and wind tunnel results for the pitching moment coefficient was not in very good agreement, because CFD predicted a much more stable projectile.

Reynier [4] focused on the numerical simulation of supersonic flows around a missile with lattice wings. The number of elements was 786432 cells for missile itself and 131072 cells for the base flow. The computational domain was extended over one missile length in the radial direction and $1 / 3$ of the missile length downstream of the base. The FLOWER code is used for the numerical simulations to solve the three-dimensional Navier-Stokes equations using a structured approach. The finite volume formulation had been used for the computations. Reasonable agreement had been found with the experimental data at different Mach numbers and low angles of attack.

Cayzac [5] studied large subsonic, transonic and supersonic flow using CFD, wind tunnel and free flight investigations to improve the knowledge of yawing and spinning projectile aeroballistics. The CFD computations concerned with a projectile geometry with a $5.6 \mathrm{~L} / \mathrm{D}$ body ratio Tangent Ogive-Cylinder-rotating band Boat-tail TOCBT. The spinning wall deviated the transversal free stream to one side, pushing the projectile to the other side. For transonic conditions, agreement between CFD, wind tunnel and free flight results, was excellent up to $20^{\circ}$ angle of attack. For supersonic conditions, agreement between computations and experiments for magnus force and moment coefficients was quite good up to $8^{\circ}$ of angle of attack for both force and moment. The use of the Spalart-Allmaras onetransport-equation turbulence model gave a satisfying agreement at moderate angle of attack.

Despirito and Sahu [6] investigated the use of viscous CFD calculations to predict the flow field and aerodynamics coefficients for a missile with grid fins in the supersonic flow regime. The commercial CFD code FLUENT was used in this investigation. The implicit coupled unstructured grid solver along with Spallart-Allmaras one equation turbulent model was used in these investigations. Second order upwind discritization was used for the flow variables and turbulent viscosity equations. The geometry and mesh were generated using the preprocessor GAMBIT. Boundary layer mesh spacing was used near the missile body and fin surfaces. The $1^{\text {st }}$ point of the surface (cell center) was between $0.004 \& 0.006$ caliber. Total number of cells was about 3.9 million with 3.2 million in the fins region. The simulations were performed in parallel using 6 processors on a Silicon Graphics Inc. (SGI), Origin 2000 with R 1200 processors. The calculations took about 4 to 6 minutes per iteration. The aerodynamic coefficients converged in about 700 to 800 iterations and about 1200 iterations for the turbulent viscosity to converge with residual $5 \times 10^{-5}$. Good agreement was found between the computed and the experimental axial force coefficient with a difference between 4 and $8 \%$. Reasonable agreement was found for normal force coefficient with difference between 8 and $16 \%$. The agreement between the computed and experimental pitching moment coefficient was not as good, with a difference between 16 and $27 \%$. Good agreement was found for the location of the center of pressure with difference of 6 and $10 \%$.

Hartman [1] prepared a paper for the working group of fluid dynamic panel of AGARD as a contribution to the "Experimental data base for computer program assessment" that is being established. This contribution contains selected data from force and surface pressure 
distribution measurement. The experimental investigations were performed in the DFLVR $1 \times 1$ Meter Transonic Wind Tunnle. The tested model consist of $1.5 \mathrm{D}$ long circular arc tangent ogive and a $20 \mathrm{D}$ long after-body of circular cross section ( $\mathrm{D}=45 \mathrm{~mm}$ body diameter). Model support had to be used since the angle of attack had varied values.

The objective of the present study is to provide a methodology for the determination of the aerodynamic coefficients of a missile of given geometry using a computational tool to get the aerodynamic data with higher accuracy compared to the experimental data obtained from wind tunnels. The computational fluid dynamics (CFD) is applied to determine the aerodynamic coefficients by using a commercial code FLUENT which solves the governing equations of the flow motion using a technique of finite volume.

\section{CFD Simulation Technique:}

FLUENT solve the governing equations for the conservation of mass, momentum, and energy within the computational domain of interest. The domain was divided into discrete control volumes using a computational grid so that the governing equations were integrated on the individual control volumes to construct algebraic equations for the discrete dependent variables such as velocities, pressure and temperature. Finally, the linearization of the discretized equations and solution of the resultant linear equation system to yield updated values of the dependent variables.

For the present study, CFD simulation is used to predict the aerodynamic drag and lift coefficients and other flow properties around the missile body. Calculations were made using the commercials CFD package FLUENT 6.2 with its pre-processor GAMBIT.

\subsection{Physical domains}

Since the target of this study is to simulate the flying of the missile consist $1.5 \mathrm{D}$ long circular arc tangent ogive and a $20 \mathrm{D}$ long after-body of circular cross section ( $\mathrm{D}=45 \mathrm{~mm}$ body diameter), and compare the results with pre-measured data from wind tunnel which simulate the flying of the missile in the air, the physical domain can be taken as the atmosphere with free stream parameter at sea level such as temperature $(250 \mathrm{c})$, density $(1.225 \mathrm{~kg} \cdot \mathrm{m} 3)$ and pressure (1 atm). The velocities of the free stream air flow were determined as needed in this study. Figure (1) shows the geometry of the missile.

\subsection{Computational domain}

The domain of solution was extended to be 20 times length downstream far from missile base, 10 times length around the missile, and 10 times length upstream far from missile nose. The sting which is the fixing tool of the model inside the wind tunnel was simulated in the computational domain as a tube connected to the missile base and extended to the end of the domain. The computational cells were concentrated near the missile surface where high gradient of flow parameter were expected, to have an accurate solution of the flow with keeping the minimum amount of meshes in the domain to save the processing time. Quadrilateral cells were used in the entire domain except at the nose sections, quadrilateral and wedge cells were used. First cells row at a distance 0.003 meter from the missile body 
for accurate calculation of the flow near the surface of the body. The total number of meshes in the domain equal 232092 meshes as shown in figure (2).

The second computational domain was the same like the first one except that the sting was removed in order to simulate the free flying of the missile. The total number of meshes in the second domain was 272635 meshes.

\subsection{Governing equations}

Based on finite volume approach the flow field is solved using the Reynolds-averaged NavierStokes (RANS) equations. The energy equation which is primarily derived from the first law of thermodynamics was used to predict temperature field. Spallart-Allmaras model will be used to model turbulent flow [7]. The Spallart-Allmaras model is a simple one-equation model based on solves a transport equation for a quantity that is a modified form of the turbulent kinematics viscosity.

In this work the standard wall function is used. The standard wall functions in FLUENT are based on the proposal of Launder and Spalding [8], and have been most widely used for industrial flows.

An important parameter is the wall shear stress ${ }^{\tau_{w}}$ (drag per unit area). Like any other stress this has dimension of [M $\times \mathrm{L}-1 \times \mathrm{T}-2]$ and hence it is possible to define a velocity scale called the friction velocity ${ }^{u_{\tau}}$. From ${ }^{u_{\tau}}$ and $v$ it is possible to form a viscous length scale defined as $\frac{v}{u_{\tau}}$, and hence a non-dimensional distance from the wall called $\mathrm{Y}+$ defined as $Y^{+}=\frac{u_{\tau} y}{v}$ where $y$ is the distance from the surface. For Spallart-Allmaras, $Y^{+}$should either be very small (of order of $Y^{+}=1$ ) or greater than 30 . The drag coefficient can be better predicted if the $Y^{+}$value is kept in the range of 30-100. Figure (3) show $Y^{+}$over the solid boundaries for Mach number 0.5 and angle of attack 2.060. It was found that the $Y^{+}$values were lied in the acceptable range.

\subsection{Boundary conditions}

Boundary conditions specify the flow variables on the boundaries of the physical model. They are, therefore, a critical component of FLUENT simulations and it is important that they are specified appropriately. There are three portal found in the computational domain, the upstream section in front of the missile nose, the lower-stream section behind the missile base, and the middle section around the missile body. Pressure far-field boundary conditions are used to define the velocity and scalar properties of the flow at all ports. The inlet Mach number is specified according the case studied in this work to be 0.5 and 1.2. The turbulence is specified at the each port by turbulent viscosity ratio. The no-slip condition is imposed on the solid surfaces of the missile and the sting.

\subsection{Solution Procedures}


FLUENT uses a control-volume-based technique to convert the governing equations to algebraic equations that can be solved numerically. A three dimensional, steady, implicit segregated solver was used. The pressure- velocity coupling was calculated through the Simple scheme. Second order upwind discretization was used for momentum, modified turbulent viscosity, and energy equations. The operating conditions were set so that the operating pressure was the atmosphere pressure.

During the solution process, the convergence can be monitored dynamically by checking residuals. The residuals must be kept on decreasing from the start to end of the iterations. Thus, the solution is converged if the residuals have decreased to a certain limit defined by the user. For most problems, the default convergence criterion in FLUENT is sufficient [9]. This criterion requires that the scaled residuals decrease to $10-3$ for all equations except the energy equation, for which the criterion is 10-6. The numerical results were obtained using PC (3.2 GHz Pentium 4), 1 GB of RAM, and 80 GB hard disk. Generally 1000-1200 initiations were required to obtain a suitable level of solution convergence, while each calculation requires about at least 8 hours of CPU time. Figure (4) shows the residuals history with the number of iterations for one of the cases studied. The residuals history was obtained for all cases studied and they behave as the case shown in shown figure.

\section{Results and Discussion:}

\section{1 model with sting}

Results will be analyzed in order to understand the three-dimensional flow over a body of revolution. Results for case of free stream Mach number equal 0.5 and angle of attack equal $2.06^{\circ}$ with a model sting were captured and displayed.

Figures (4) and (5) show the history of the drag and lift coefficient respectively with the iterations. Drag coefficient had a constant value after about 1050 iterations while the lift coefficient had a constant value after about 1100 iterations. The final total drag coefficient obtained is about 0.37188 while the final lift coefficient obtained is about 0.115458 .

Comparing the computational results with the experimental results which are 0.354329 for drag coefficient and 0.12243 for lift coefficient, the accuracy of these results can be estimated as follows:

For drag coefficient $\quad=4.9 \%$

For lift coefficient $\quad=-5.6 \%$

\section{2 model without the Sting}

For better simulation of flow conditions during the missile free flight, the body support is removed and the flow is solved around the body without the sting. Next results are for case of Mach number $\mathrm{M}=0.5$ and angle of attack $\alpha=2.06 \mathrm{o}$.

\subsubsection{Drag and lift convergence history}

Figures (6) and (7) show the history of the drag and lift coefficient respectively with the iterations. Drag coefficient had a constant value after about 1200 iterations while the lift 
coefficient had a constant value after about 1000 iterations. The final total drag coefficient obtained is about 0.45262 while the final lift coefficient obtained is about 0.1191 .

\subsubsection{Contours of static pressure and Mach number distribution}

From figures (8), (9), and (10), it can be noticed that there is no more symmetry distribution of static pressure contours between upper and lower half of the symmetry plane. The region in which the value of static pressure is lower than the free stream pressure has a large area at the upper half of the symmetry plane. For Mach number 0.5 and angle of attack 2.06o, the highest static gauge pressure was at the nose tip and it was equal about $16288.7 \mathrm{~Pa}$ while its value for Mach number 1.2 was about $130000 \mathrm{~Pa}$. From figures it can be noticed that the static pressure was decrease at the missile base where the circulation of the flow exist. The static gauge pressure at the missile base for Mach number 0.5 was about $-5921.5 \mathrm{~Pa}$ while its value for Mach number 1.2 was $-35000 \mathrm{~Pa}$.

Also, the Mach number distribution was not symmetric between upper and lower half of the symmetry plane. From Figures $(11-14)$ the boundary layer build up in the upper half is greater than the lower half that is because of the presence of the angle of attack.

Figure (15) show the Mach number distribution at the nose section of the missile, while figures (16) and (17) show the Mach number distribution behind the base of the body. The wake region, in which the Mach number is minimum value, is clear from the figures. The maximum Mach number of the flow was at the intersection between missile nose and missile body where an expansion shock wave occurred. The maximum Mach number in case of free stream Mach number 0.5 was 0.566 while its value for free stream Mach 1.2 was about 1.5. On the other hand, the lowest Mach number was at the missile base where its value in case of free stream Mach 0.5 was about 0.032 while its value in case of free stream Mach 1.2 was about 0.1

\subsection{Path lines of air flow over the missile body}

Figure (18) and (19) show the x-velocity vectors at the base of the missile for free stream Mach number equal 0.5, angle of attack 2.060 and free stream Mach number 1.2, angle of attack 13.60 respectively. From figures it was clear that the circulations were occurred at the base of the missile and the affect of the angle of attack appeared in the figure (19).

Figure (20) shows the path lines of the air flow around the missile body. From figure it is clear that the air flow is deflected near the nose of the missile in order to keep it self parallel to the surface. Figure (21) shows the air flow behind the base of the missile, the wake behind the base is cleared in the figure.

\subsection{Comparison between experimental and numerical coefficients}

From Figure (22), it is clear that the comparison between experimental and computer results shows a good agreement and a small relative error. The highest curve of the figure shows the 
axial force coefficient of the missile without a sting, so, the value of axial force coefficient increases due to base drag. Figure (23) shows the axial force coefficient for Mach number $M=1.2$, from figure it is clear that the error is increased due to increases of Mach number. The maximum relative error is about $10 \%$. Figures (24) and (25) show that the absence of the sting did not affect the normal force coefficient. A good agreement has been found from comparing the computer and experimental results. The pitch moment was taken as a moment around the tip of the nose in order to compare the numerical results with the experimental results. Figures (26) and (27) show the pitch moment coefficients at different angles of attack for $\mathrm{M}=0.5$ and $\mathrm{M}=1.2$ respectively as obtained experimentally and numerically.

\subsection{Magnus Effect}

Magnus force and moments are generated by the distorted velocity distribution which results from a spinning body at angle of yaw. This work will report the results of spinning effect in order to display the Magnus affects that would be useful in the design of artillery projectiles. The body of revolution was solved here with an additional wall condition which is the spinning condition. It was solved for a Mach number $M=0.5$ and $M=1.2$ with an angle of attack equal 2.060 and spinning rate equal 20000 r.p.m.. Results were compared with the results without spinning for same flight conditions in order to understand the spinning effects.

Boundary layer thickness was calculated as the distance normal to the surface at which the $x$-component of the velocity equal 0.999 from the $x$-component velocity of the free stream. Figure (28) compares the boundary layer thickness for the missile body with and without spinning for Mach number equal 0.5 and angle of attack equal 2.06o. Next table compares the values of the aerodynamic coefficient and magnus coefficient in case of spinning and non-spinning projectile for Mach number equal 1.2 and angle of attack equal 2.06o.

Since many projectiles are spin-stabilized bodies of revolution, the magnus force would be generated by spin-induced distortion of velocity distribution. Although the magnus force is only one-tenth to one-hundredth of the normal force [10], it is a critical parameter in determining the dynamic stability of a projectile. Thus, it is desirable to reduce the magnus force for improving the projectile performance. One of the methods used to improve the spinning projectile performance is using of the porous surface for the projectile body. When a porous surface and a cavity beneath are placed under a shock wave, the pressure difference across the shock induces a self-bleed upstream flow through the cavity. The combination of blowing upstream and suction downstream of the shock causes the original normal shock wave to become a weaker shock wave system. The cavity can provide the circumferential pressure communication. Thus, the porous surface is likely to reduce magnus force by equalizing the circumferential surface pressure [10].

Table (1): Aerodynamic coefficients for spinning body

\begin{tabular}{l|l|l|l}
\hline $\begin{array}{l}\text { Aerodynamic } \\
\text { coefficients }\end{array}$ & Spinning & Non-spinning & $\begin{array}{l}\text { Relative } \\
\text { difference }\end{array}$ \\
\hline $\mathbf{C}_{\mathrm{A}}$ & 0.759166 & 0.757097 & $0.2725 \%$ \\
$\mathbf{C}_{\mathrm{N}}$ & 0.12708 & 0.1172824 & $7.708 \%$ \\
$\mathbf{C}_{\mathrm{Z}}$ (magnus coefficient) & -0.038394 & 0.00006373 & \\
\hline
\end{tabular}




\section{Conclusions and recommendations}

Implicit segregated structured grid solver was used in this study. Second order upwind discritization was used for the flow variables and turbulent viscosity equations. SpallartAllmaras turbulent model was used to simulate the turbulent flow over the missile body. Quadrilateral cells were used in the entire domain except at the nose sections, quadrilateral and wedge cells were used. First cells row at a distance 0.003 meter from the missile body. The total number of meshes in the domain equal 232092.

The main conclusion of this study can be summarized as:

1- the computer numerical code FLUENT has proven to offer good acceptance results as compared with the experimental results for the case of three-dimensional flow around a body of revolution.

2- Base drag mainly effected with the present of the sting during measuring the drag coefficient in the wind tunnel.

3- High rate spinning of the body of revolution generates a side force affect the body of the missile while the axial force don't mainly affected with the spinning.

4- A slightly effect of the spinning appears on the normal force affecting the missile body. The main recommendation of this study can be summarized as:

1- Use high speed computers to predict the presence of the side slip angle of the missile.

2- Use the parallel processing to decrease the time of the processing and increase the number of grid cells to get higher accuracy.

\section{References:}

[1] Hartmann K., "1.5 D Ogive-Circular Cylinder Body, L / D = 21.5", AGARD Advisory report No. 138, Experimental Data Base for Computer Program Assessment, Report of the Fluid Dynamics Panel Working Group 04.,

[2] Byung-Young Min, Jae-Woo Lee, Yung-Hwan Byun, "Numerical Investigation of Shock Interaction Effect on the Lateral Jet Controlled Missile", Aerospace Science and Technology 10, February 2006.

[3] Nicolas Parise and Alain Dupuis, "Numerical Computations of Subsonic and Supersonic Flow Choking Phenomena in Grid Finned Projectiles", 22nd International Symposium on Ballistics, Canada, 2005.

[4] Philippe Reynier, Uwe Reisch, Jose-Maria Longo, Rolf Radespiel, "Flow Predictions around a Missile with Lattice Wings Using the Actuator Disc Concept", Aerospace Science and Technology 8, 20 April 2004.

[5] Cayzac R. et. al, "Analysis of static and dynamic stability of spinned projectiles", 21st International Symposium on Ballistics, Canada, 19-23 April 2004. 
[6] J. DeSpirito and J. Sahu, "Vicious CFD Calculations of Grid Fin Missile Aerodynamics in the Supersonic Flow Regime", 39th Aerospace Science Meeting \& Exhibit, 8-11 January 2001.

[7] P. Spalart and S. Allmaras. A One-Equation Turbulence Model for Aerodynamic Flows. Technical Report AIAA-92-0439, American Institute of Aeronautics and Astronautics, 1992.

[8] B. E. Launder and D. B. Spalding. The Numerical Computation of Turbulent Flows. Computer Methods in Applied Mechanics and Engineering, 3:269-289, 1974.

[9] FLUENT user guide. "FLUENT.INC, February 2003".

[10] Shing-Ching Onn, "Computational Drag and Magnus Force Reduction for a Transonic Spinning Projectile using Passive Porosity", Computer Methods in Applied Mechanics and Engineering, April 2000.
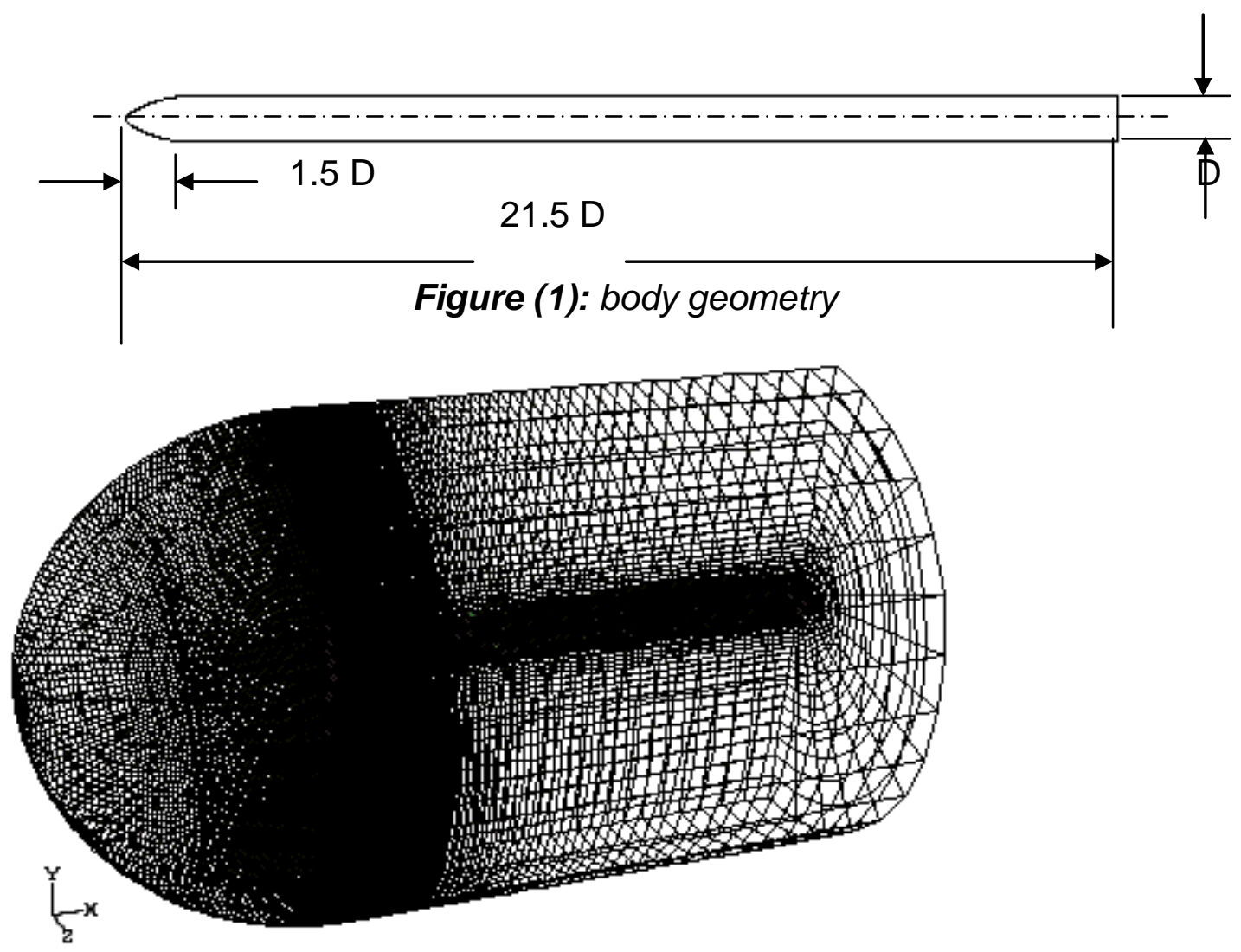

Figure (2): Computational domain 


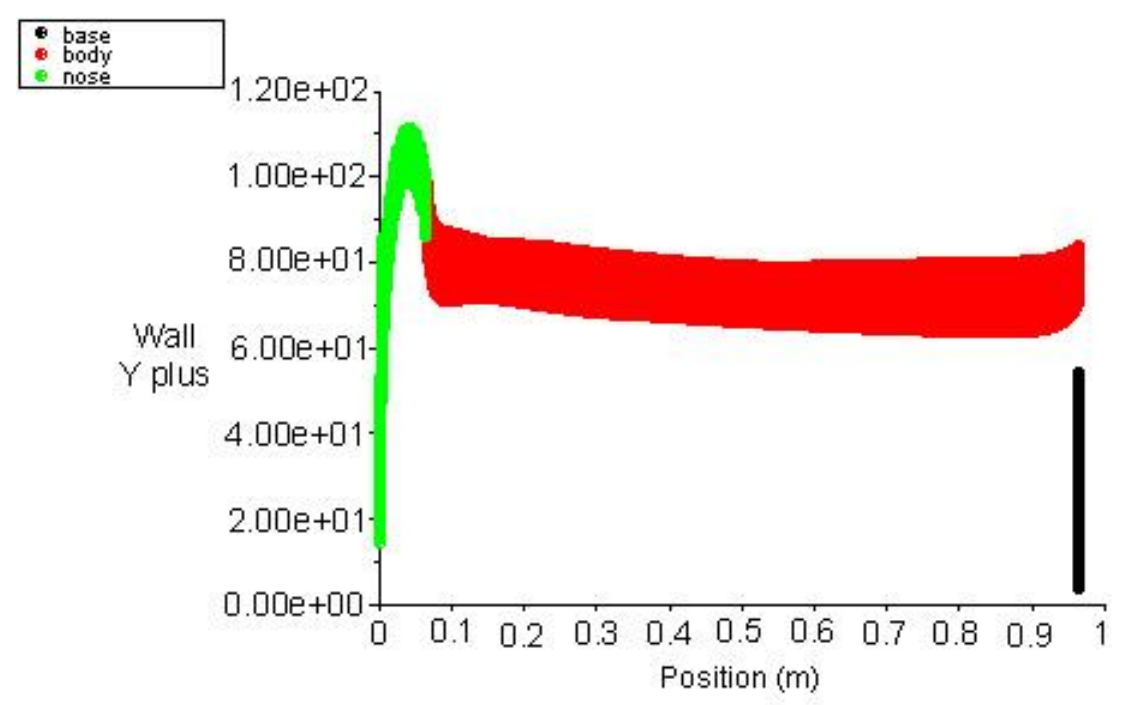

Figure (3): $Y+$ values for $M=0.5$ and $\alpha=2.060$ without sting

\begin{tabular}{|c|}
\hline Residuals \\
\hline continuity \\
x-velocity \\
y-velocity \\
\hline energy \\
nut \\
\hline
\end{tabular}

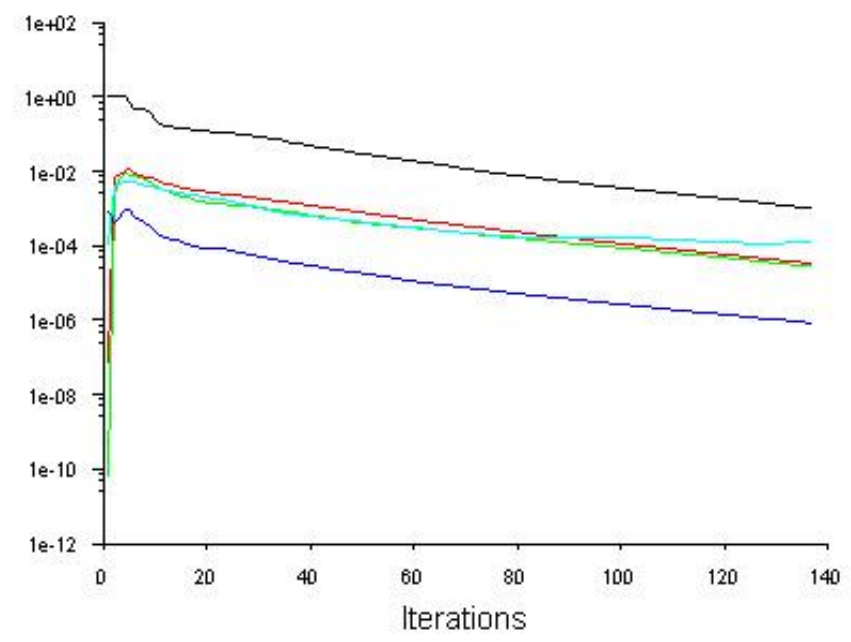

Figure (4): Residuals history for $M=0.5, \alpha=2.060$

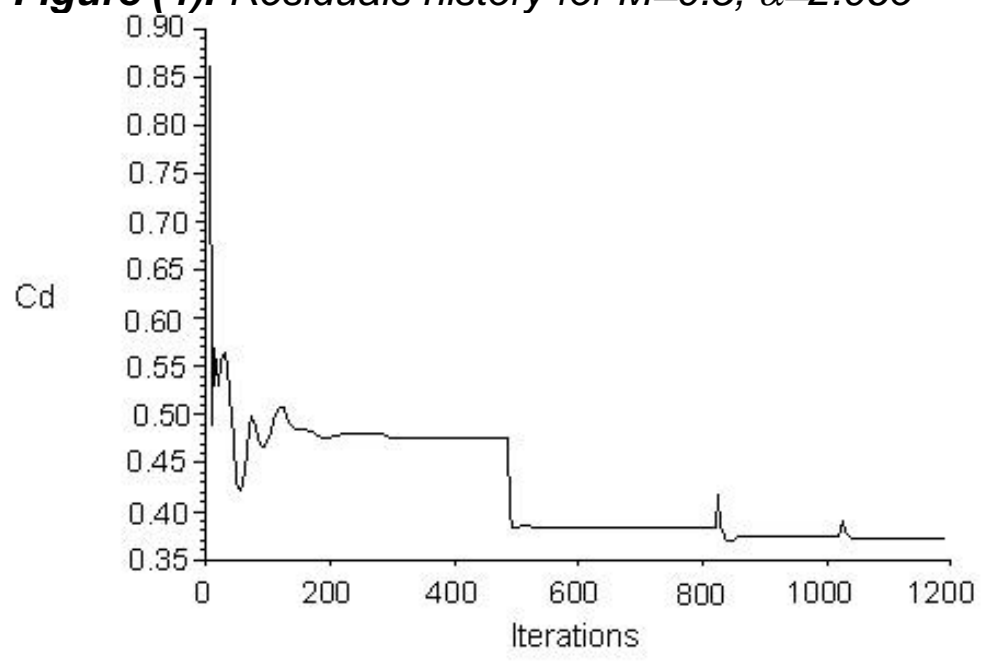

Figure (5): Drag convergence history for $M=0.5$ and $\alpha=2.060$ with sting 


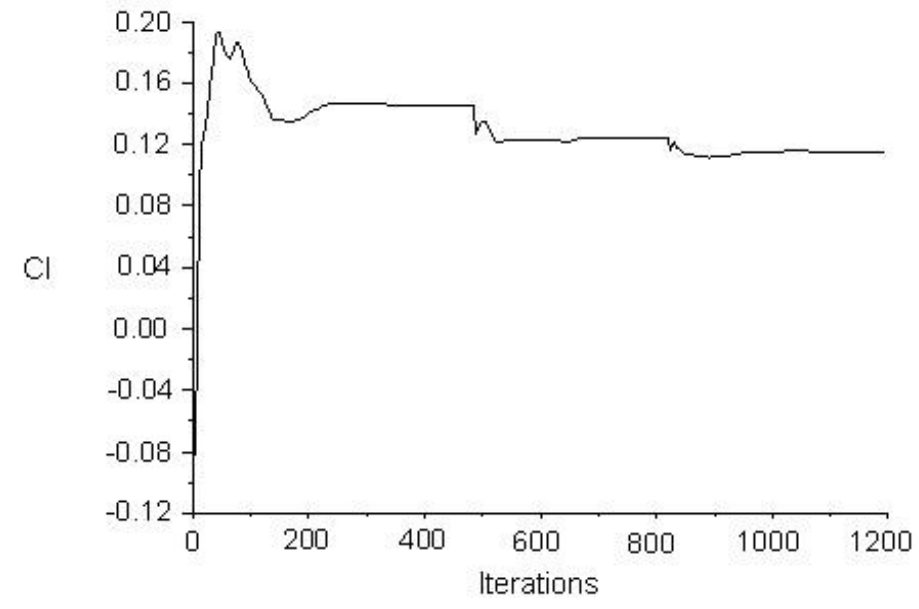

Figure (6): Lift convergence history for $M=0.5$ and $\alpha=2.060$ with sting

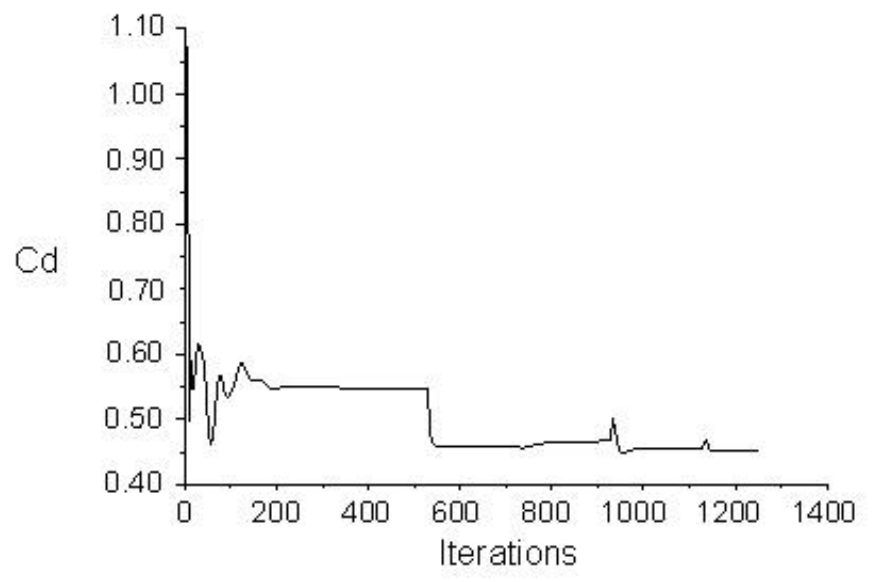

Figure (7): Drag convergence history for $M=0.5$ and $\alpha=2.060$ without sting

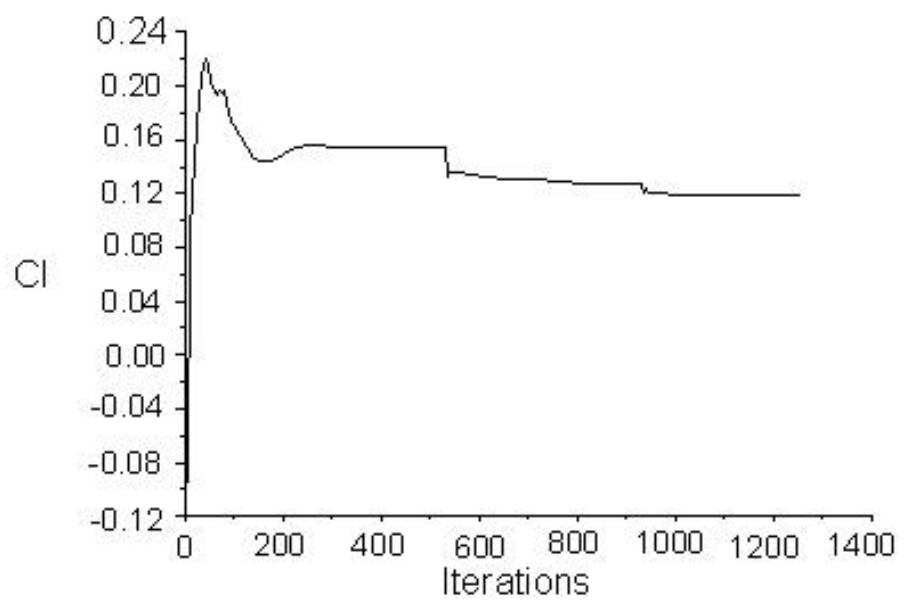

Figure (8): Lift convergence history for $M=0.5$ and $\alpha=2.060$ without sting 


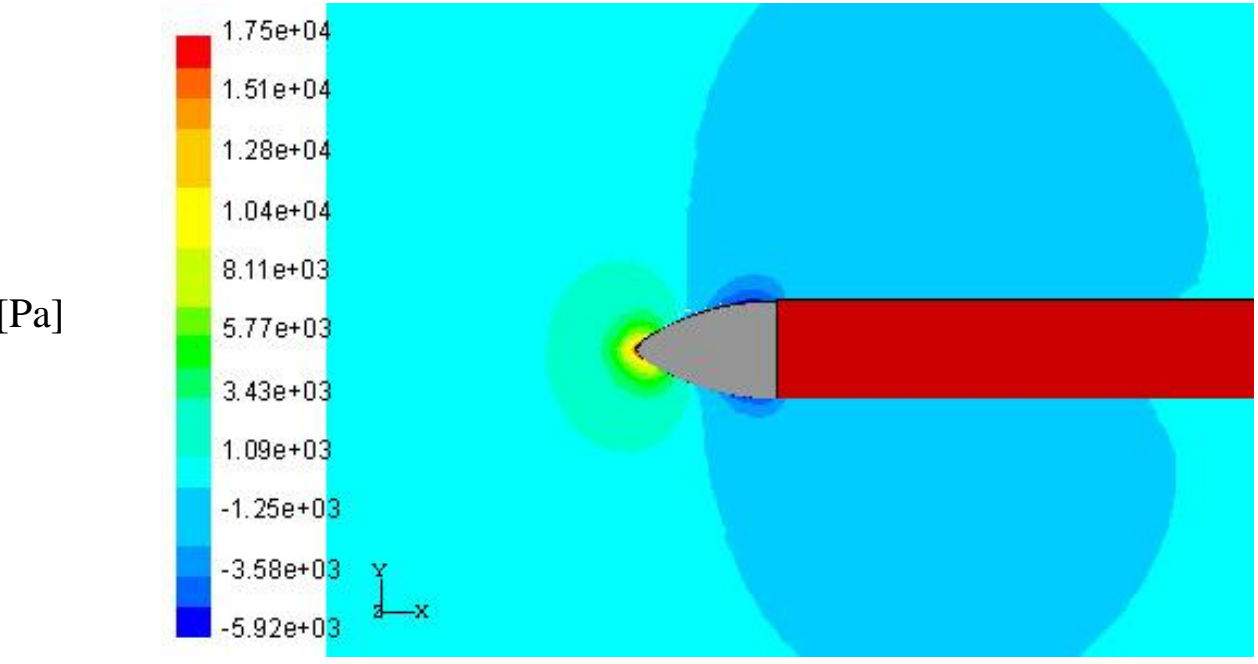

Figure (9): Contours of static pressure over symmetry plane, $M=0.5, \alpha=2.060$

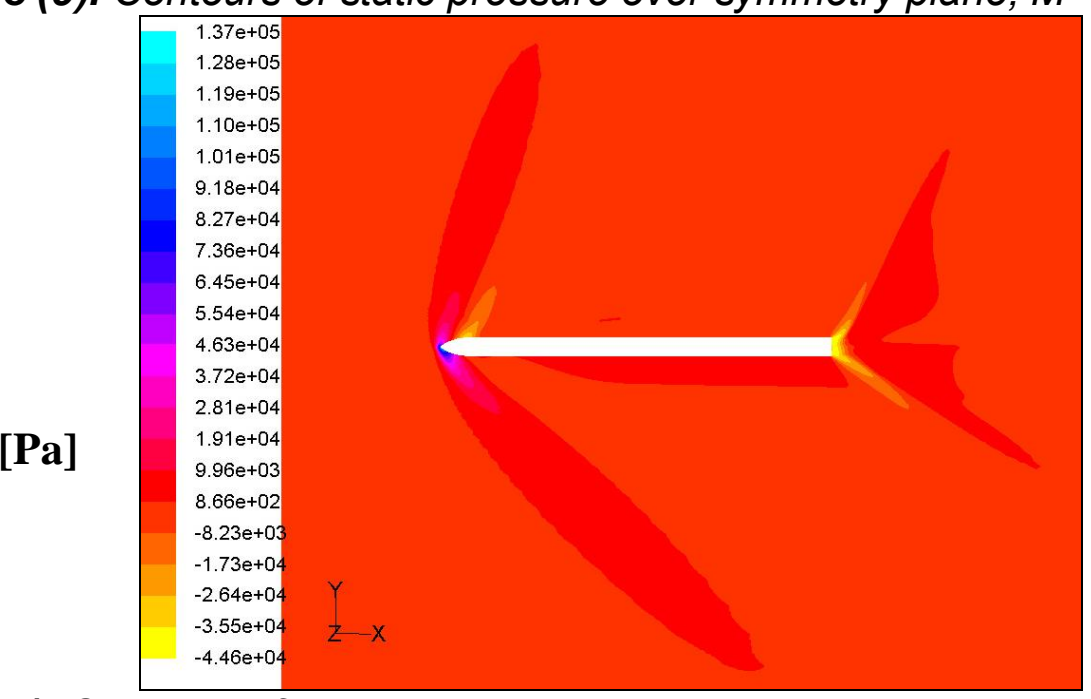

Figure (10): Contours of static gauge pressureover symmetry plane, $M=1.2, \alpha=13.60$

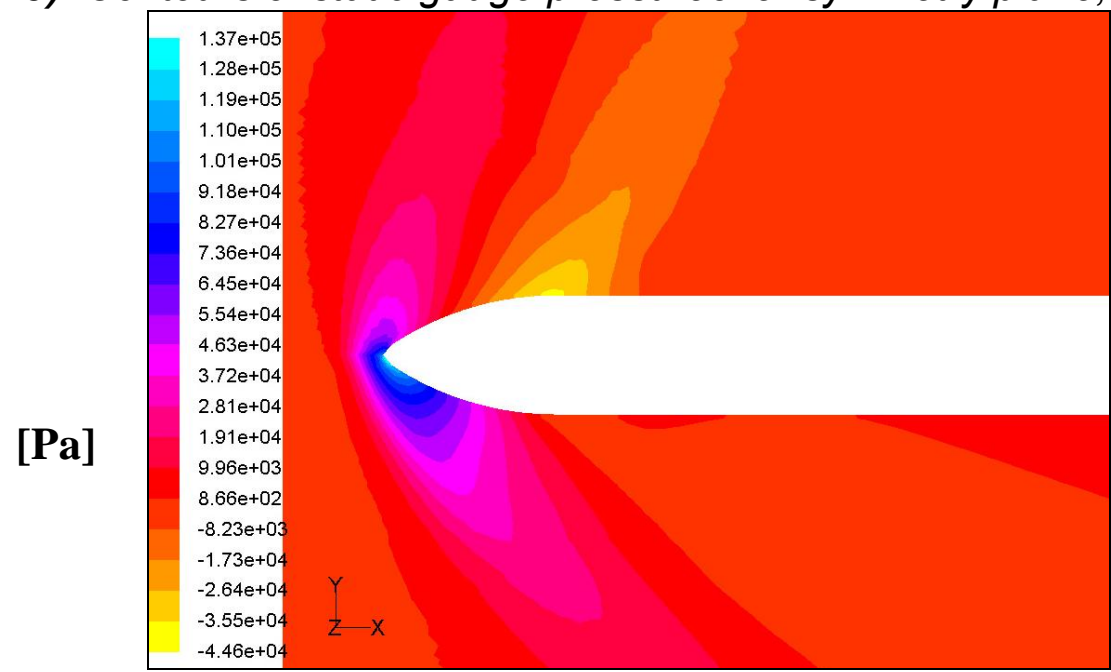

Figure (11): Contours of static gauge pressure oversymmetry plane, $M=1.2, \alpha=13.60$ 


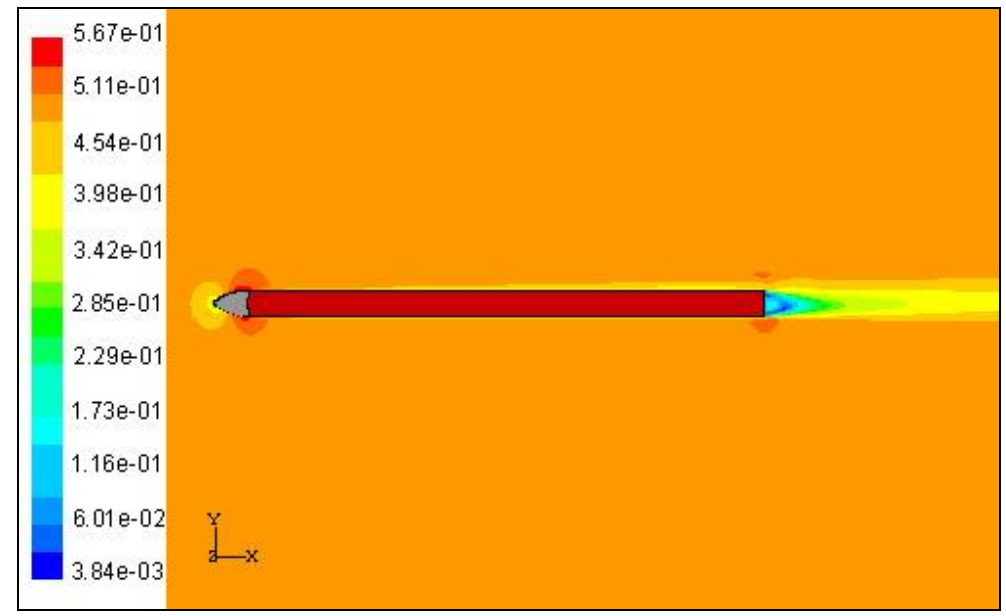

Figure (12): Mach number distribution $M=0.5, \alpha=2.060$

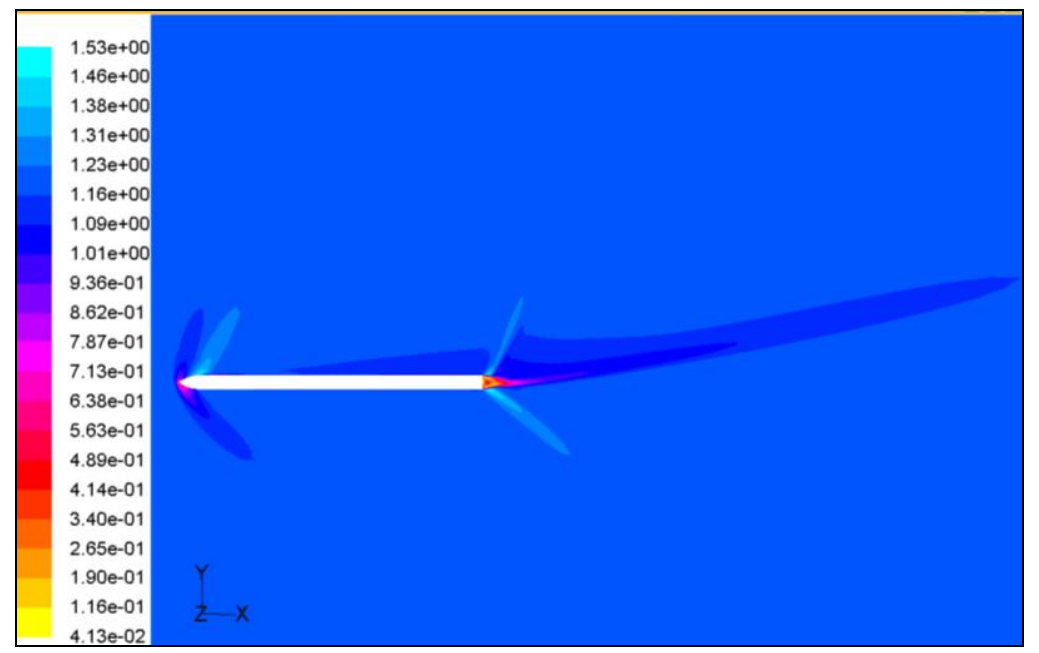

Figure (13): Mach number distribution $M=1.2, \alpha=13.60$

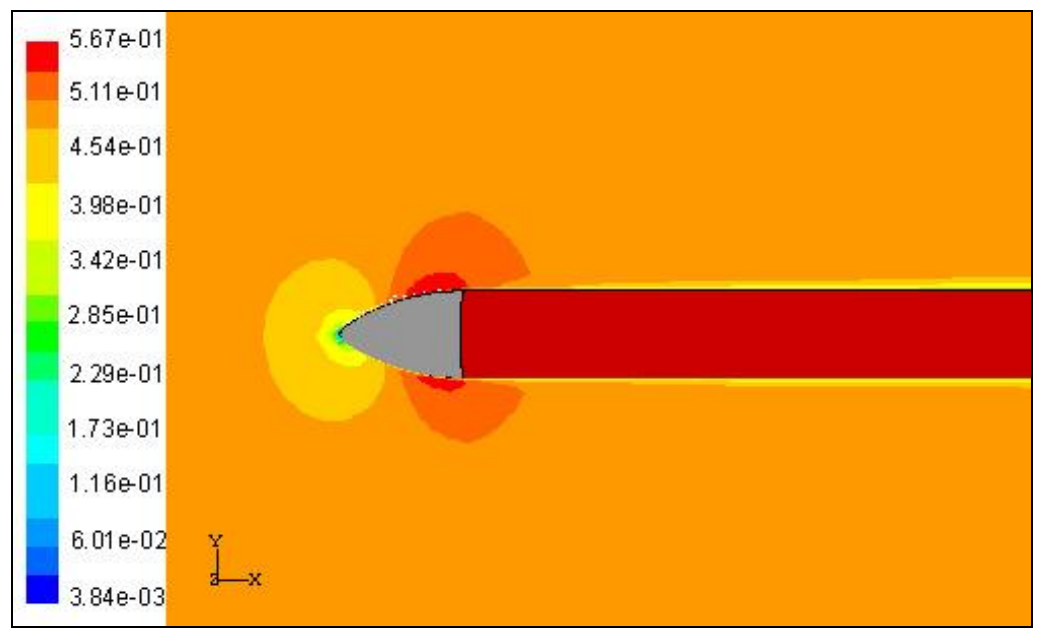

Figure (14): Mach number distribution nose sectionfor $M=0.5$ and $\alpha=2.060$ 


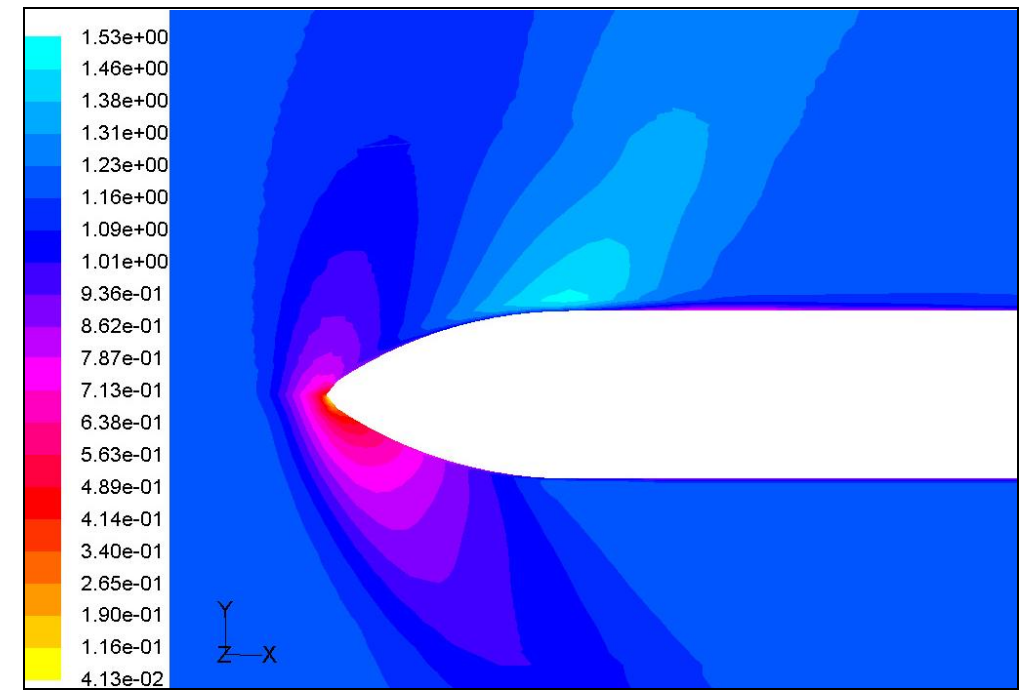

Figure (15): Mach number distribution nose sectionfor $M=1.2$ and $\alpha=13.60$

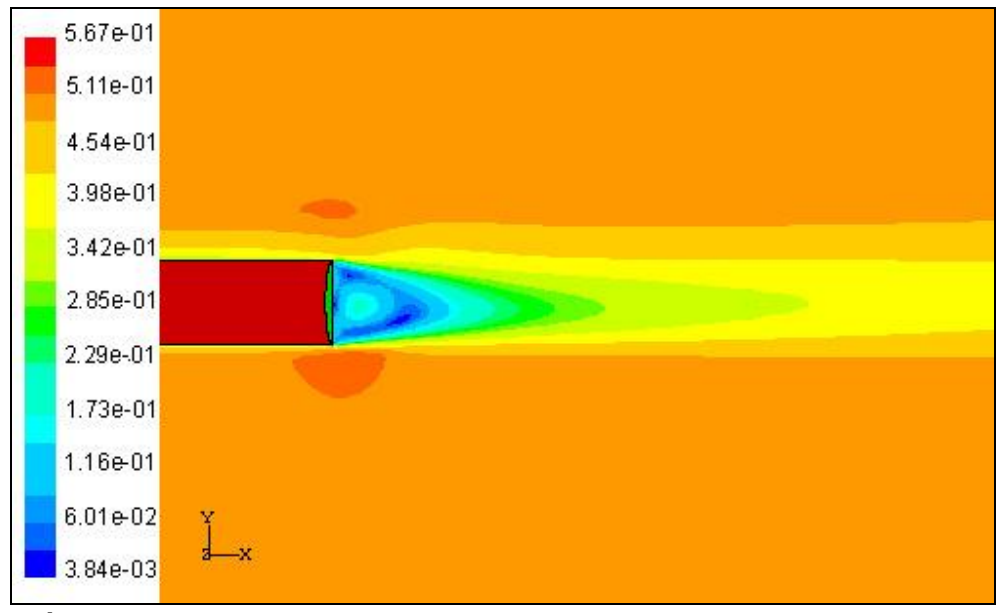

Figure (16): Mach number distribution at base section $M=0.5, \alpha=2.060$

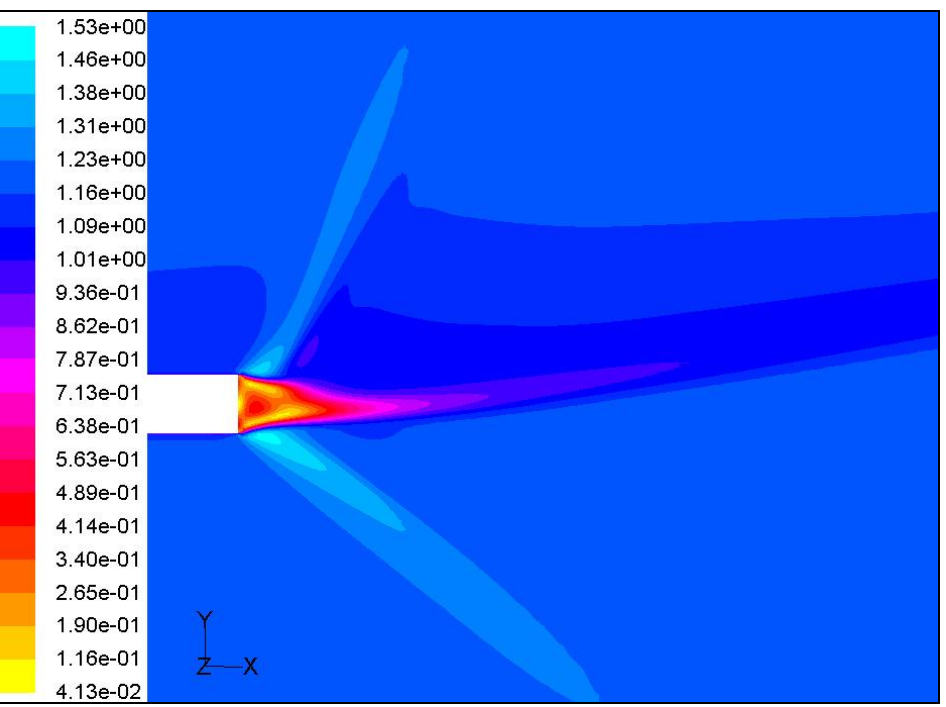

Figure (17): Mach number distribution at base section $M=1.2, \alpha=13.60$ 


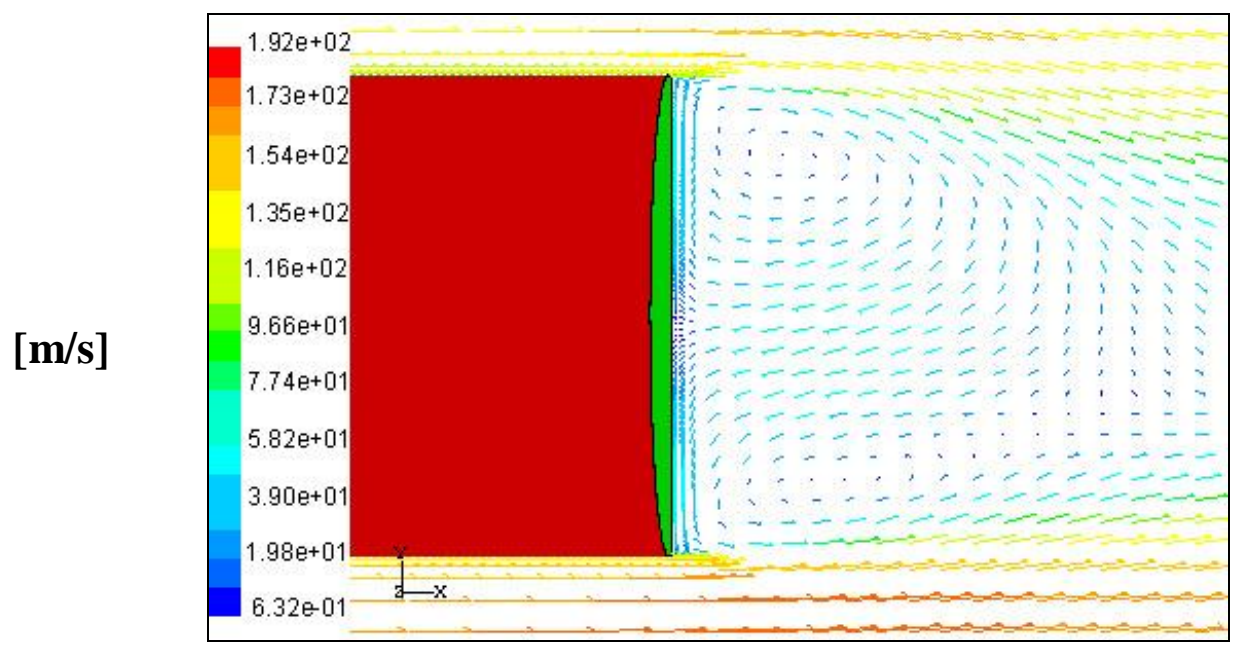

Figure (18): $x$-velocity vector at base section for $M=0.5, \alpha=2.060$

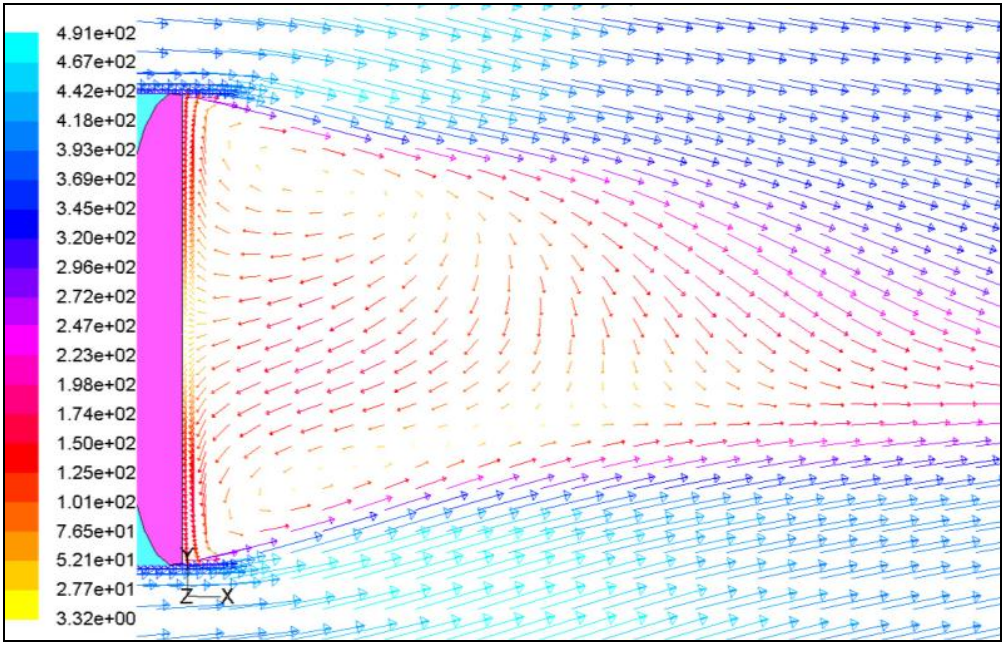

Figure (19): $x$-velocity vector at base section for $M=1.2, \alpha=13.60$

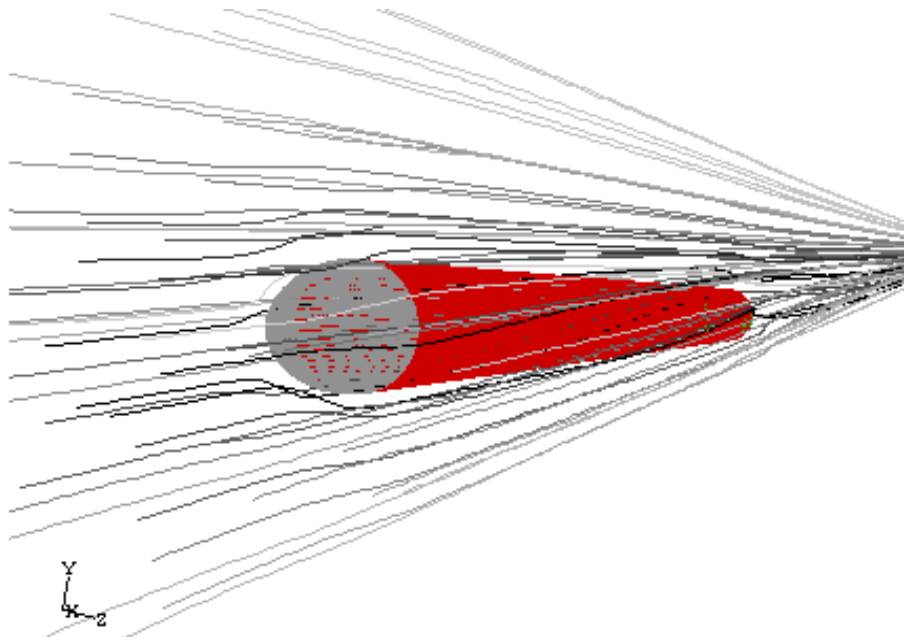

Figure (20): Path lines over the missile body for $M=0.5, \alpha=2.060$ 


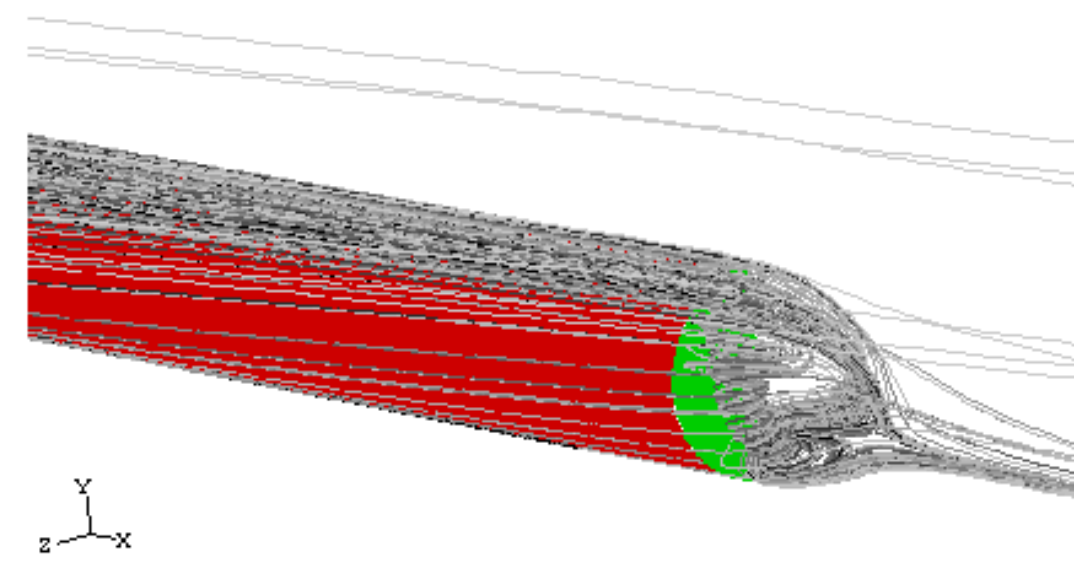

Figure (21): Path lines over missile base for $M=0.5, \alpha=2.060$

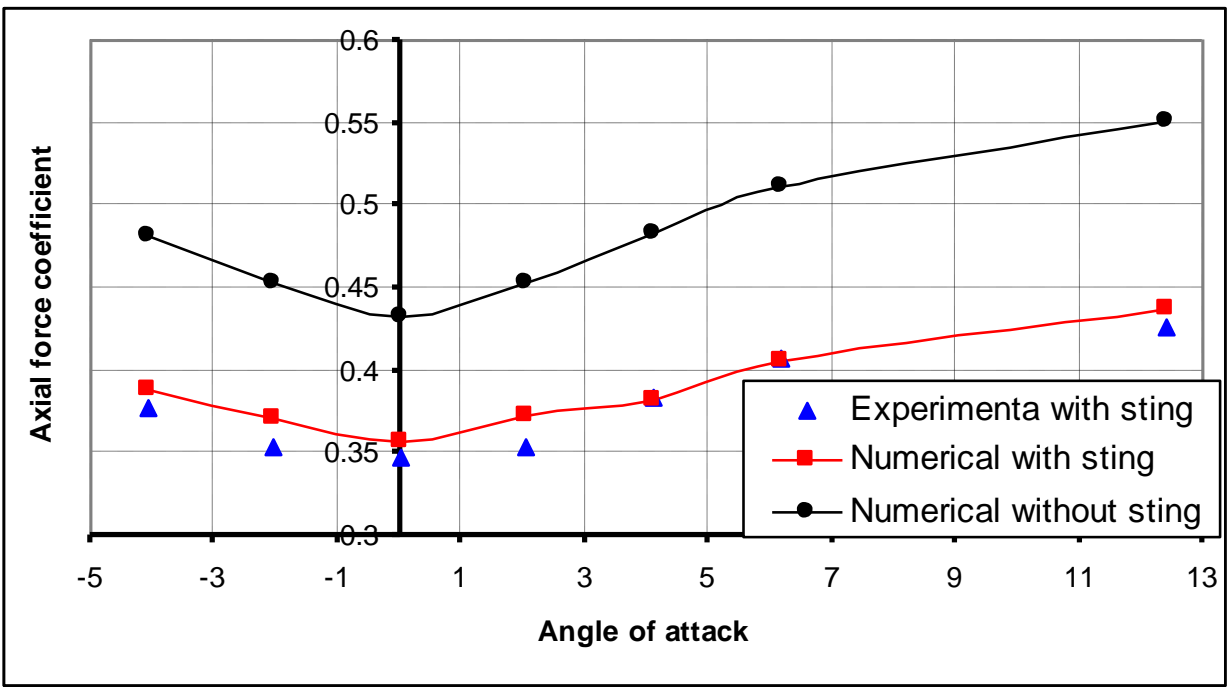

Figure (22): Axial force coefficients for $M=0.5$

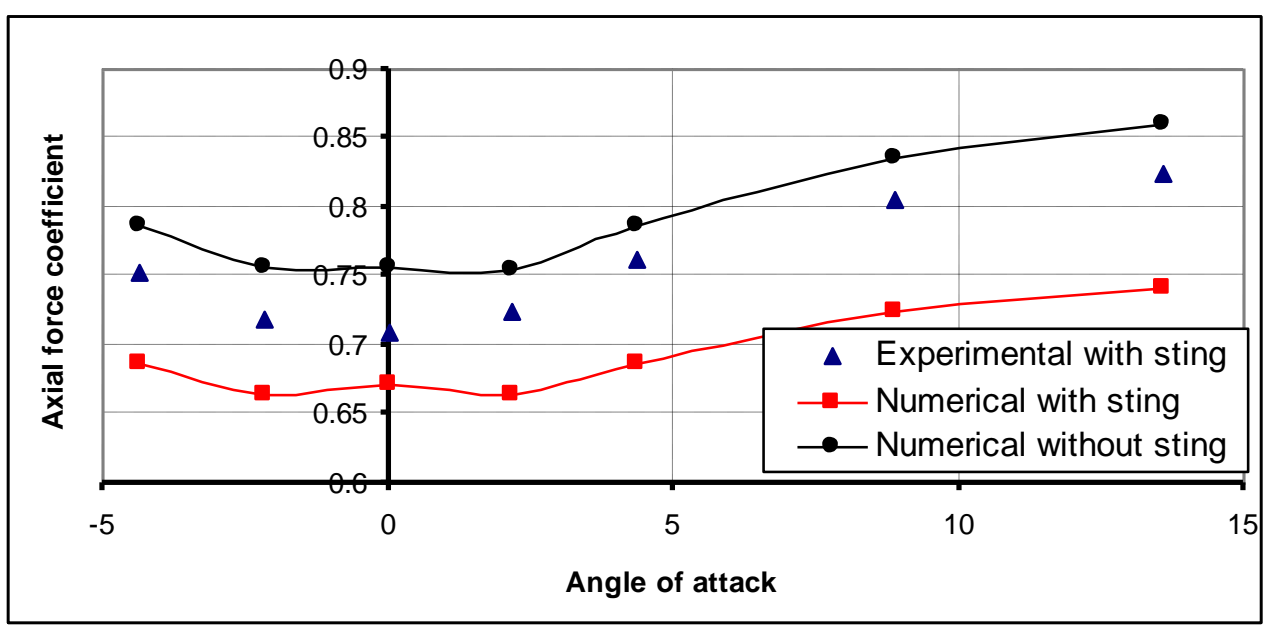

Figure (23): Axial force coefficients for $M=1.2$ 


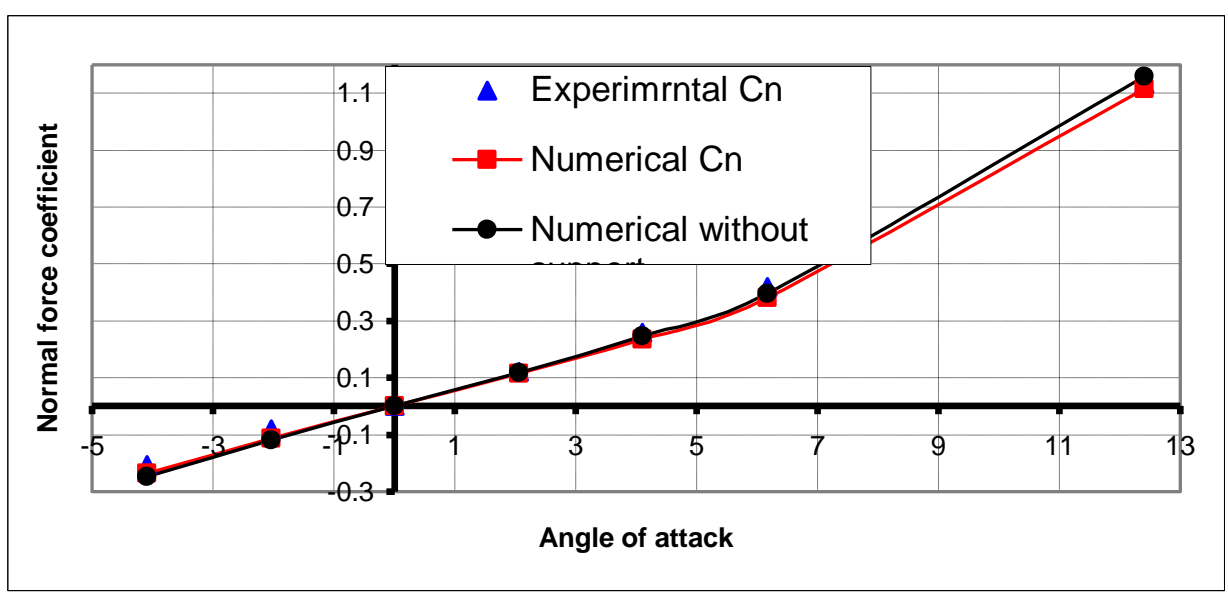

Figure (24): Normal force coefficients for $M=0.5$

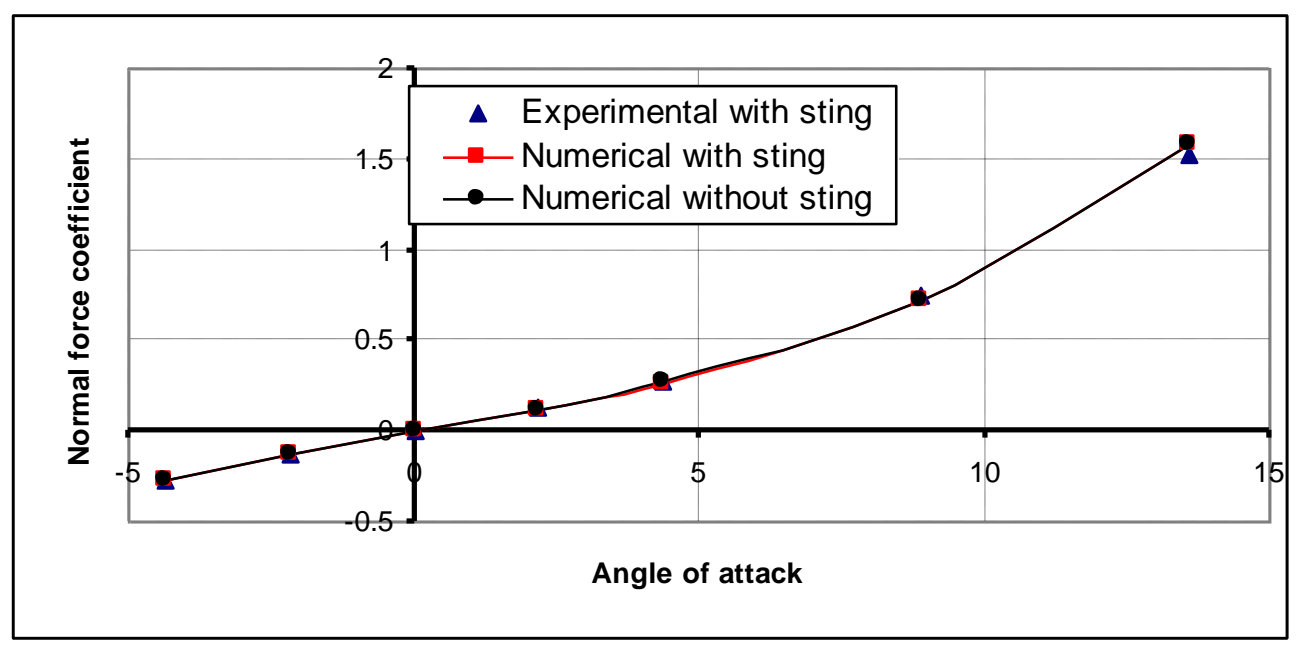

Figure (25): Normal force coefficients for $M=1.2$

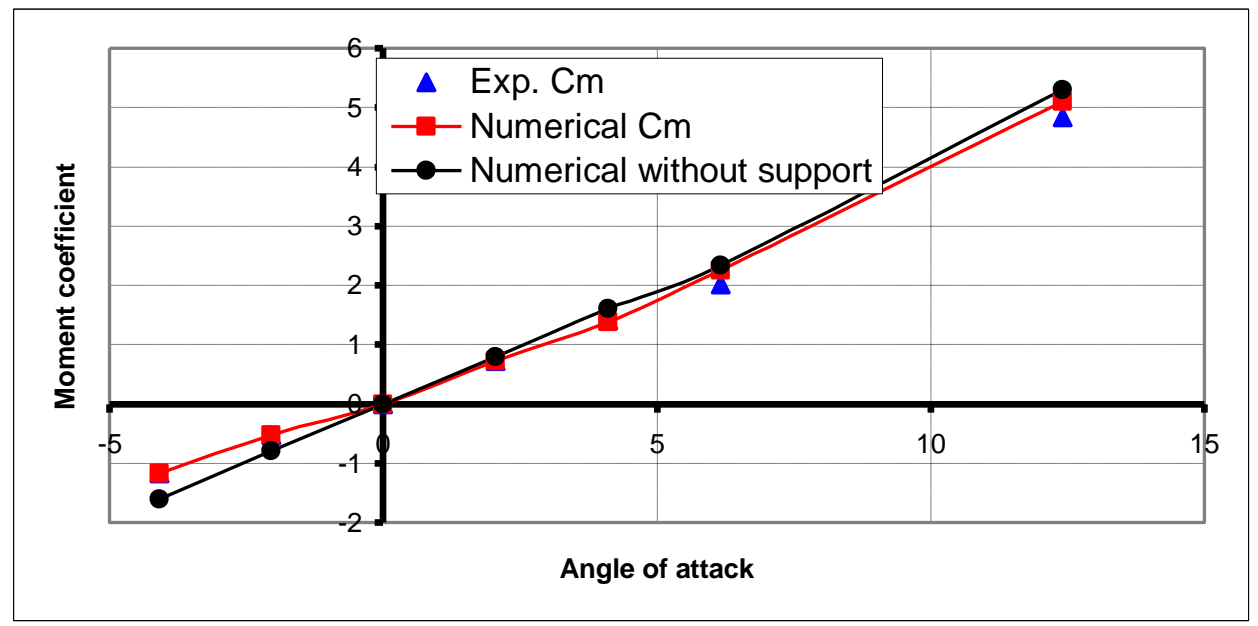

Figure (26): Pitch moment coefficient for $M=0.5$ 


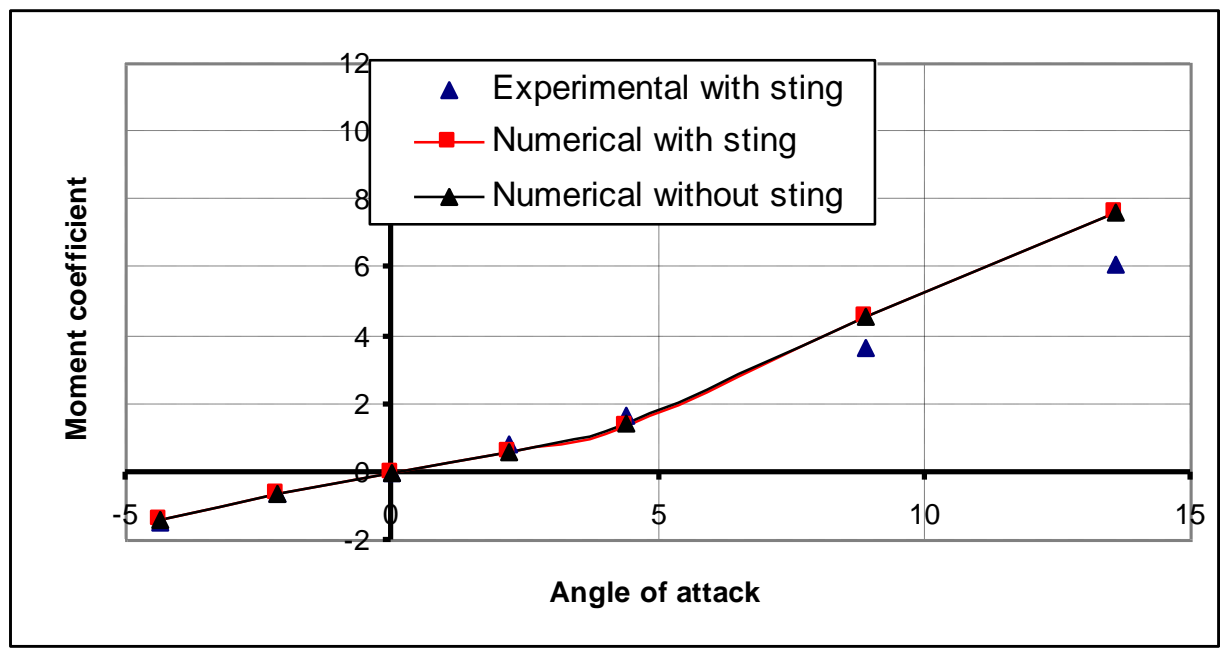

Figure (27): Pitch moment coefficient for $M=1.2$
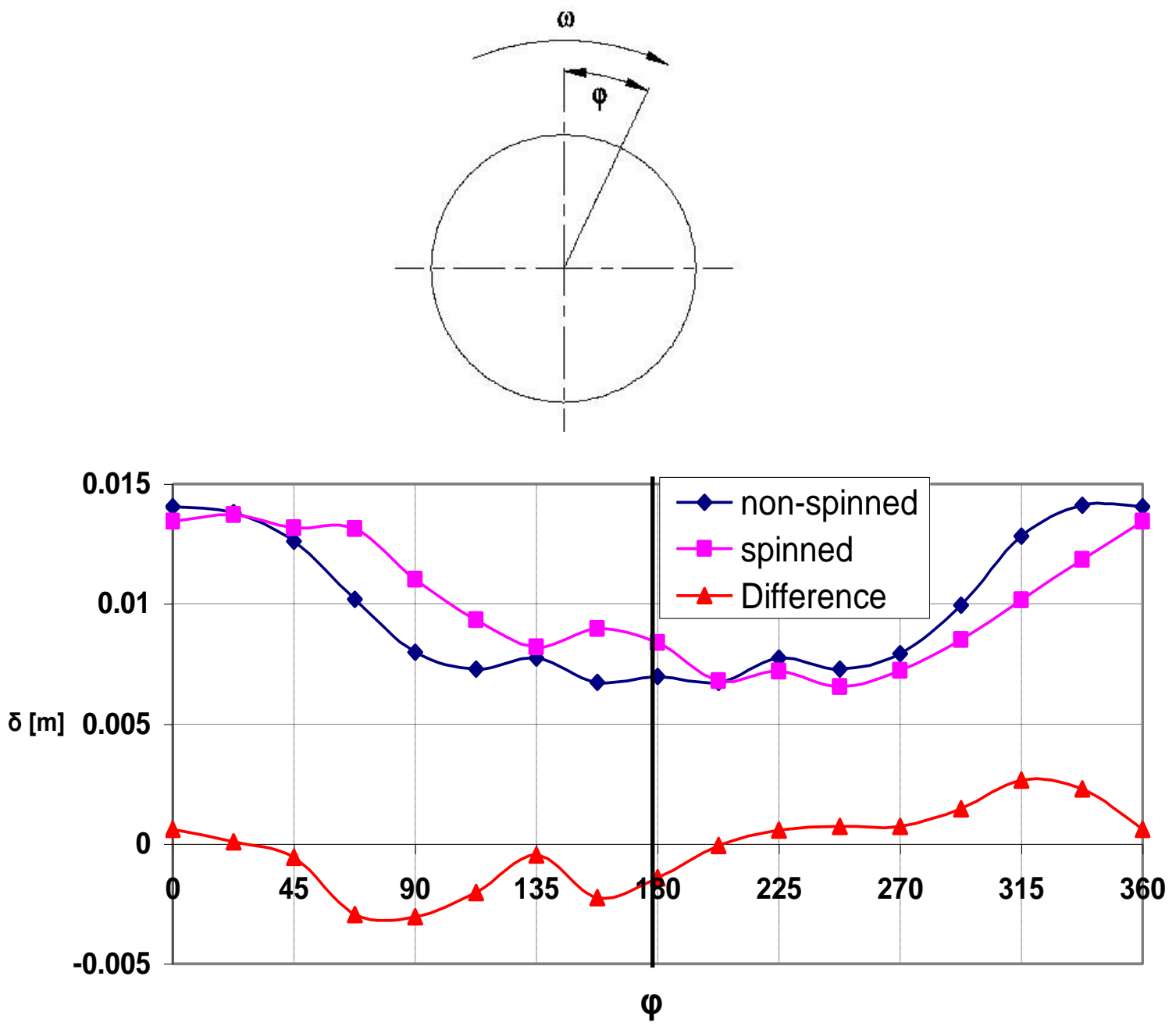

Figure (28): Boundary layer thickness for $M=0.5$. 